\title{
COMUNICAÇÃO
}

\section{APLICAÇÃO DO MÉTODO QFD NA AVALIAÇÃO DO PERFIL DO CONSUMIDOR DE ABACAXI 'PĚROLA'}

\section{Consumer profile evaluation by quality function development for a pineapple}

\author{
Ana Carolina Almeida Miguel ${ }^{1}$, Marta Helena Fillet Spoto², Camila Abrahão \\ Paula Porrelli Moreira da Silva ${ }^{4}$
}

\begin{abstract}
RESUMO
A busca pela longevidade e a procura por alimentos mais saudáveis fizeram com que os consumidores se tornassem cada vez mais exigentes. Diante disso, procurou-se estabelecer o comportamento de compra dos consumidores de abacaxi no Mercado Municipal de Piracicaba (SP) através do método de Desdobramento da Função Qualidade (QFD) e, com base nas respostas obtidas nos questionários aplicados, traçou-se o perfil dos consumidores, destacando-se suas preferências, costumes, reclamações e exigências. Verificou-se que é a mulher que realiza as compras do abacaxi, com preferência pelo consumo na forma in natura. Encontrou-se insatisfação de 80,1\% dos entrevistados quanto à qualidade do abacaxi, sendo a elevada acidez, a principal causa de descontentamento. Logo, a qualidade do abacaxi não correspondia àquela indicada pelos consumidores (casca sem defeitos, coloração amarelada ou mista, tamanho grande, boa aparência interna demonstrando que está sadio, textura firme, aroma característico, baixa acidez, sabor doce, maduro do ponto de vista fisiológico e suculento). Diante da insatisfação dos consumidores e considerando-se que o abacaxi é consumido preferencialmente in natura, deve-se atentar para a preservação da sua aparência e qualidade sensorial. A opinião dos consumidores deve ser considerada na tentativa de identificar os pontos que devem ser melhorados dentro da cadeia de comercialização, a fim de minimizar as perdas e promover a melhoria e a manutenção da qualidade do produto final.
\end{abstract}

Termos para indexação: Ananas comosus, método QFD, mercado consumidor.

\begin{abstract}
The search for longevity and the demand for healthy food have made consumers more conscious. A study was carried out to evaluate the buying habits of pineapple consumers in the Municipal Market of Piracicaba (São Paulo State, Brazil) by the Quality Function Development (QFD) Method. With the answers from the questionnaire handed to the consumers, it was possible to determine the preferences, habits, complaints and demands. It was verified that it is the woman who does the buying and that pineapples are consumed raw. $80.1 \%$ of those interviewed complained about the quality and the high acidity to the pineapple was the main complaint. The quality of the pineapples displayed do not live up to customer expectations (damage, color, size, appearance, firmness, flavor, low acidity, sweetness, maturity and succulency). Due to the customers' complaints and considering their preference for fresh pineapples, special attention must be given to the appearance and sensory quality. The opinion of the consumers must be considered in order to identify the characteristics that should be improved in trade to minimize the losses, to promote the improvement and the maintenance of the final product quality.
\end{abstract}

Index terms: Ananas comosus, QFD method, consumer market.

\section{(Recebido em 29 de março de 2006 e aprovado em 20 de setembro de 2006)}

A produção brasileira de abacaxi é quase toda destinada ao mercado interno, com predomínio do consumo do produto na forma in natura, sendo que o restante é destinado à industrialização e exportação.

Nos últimos anos, tem ocorrido mudança significativa nos hábitos alimentares da população brasileira (SOUZA, 2001). A busca da longevidade e da qualidade de vida faz com que as pessoas procurem alimentos mais saudáveis, aumentando o consumo de frutas e hortaliças frescas em detrimento dos produtos industrializados. Este fato leva à necessidade de estudos que promovam o aumento da quantidade, aliada à melhoria da qualidade final do produto oferecido ao consumidor.

O abacaxi é muito apreciado por grande parte dos consumidores de frutas, mas por outro lado, esta é com certeza uma das frutas comercializadas que apresentam

\footnotetext{
'Engenheira Agrônoma, Mestranda em Ciência e Tecnologia de Alimentos - ESALQ/USP - Avenida Pádua Dias, 11 - Cx. P. 9 - 13.418-90 Piracicaba, SP - acmiguel@esalq.usp.br

${ }^{2}$ Engenheira Agrônoma, Dra, Professora do Departamento de Agroindústria, Alimentos e Nutrição - ESALQ/USP - Avenida Pádua Dias, 11 - Cx. P. 9 13.418-90 - Piracicaba, SP - mhfspoto@esalq.usp.br

${ }^{3}$ Graduanda em Engenharia Agronômica da ESALQ/USP - Avenida Pádua Dias, 11 - Cx. P. 9 - 13.418-90 - Piracicaba, SP - abrahao@esalq.usp.br ${ }^{4}$ Engenheira Agrônoma, Mestranda em Ciência e Tecnologia de Alimentos, ESALQ/USP - Avenida Pádua Dias, 11 - Cx. P. 9 - 13.418-90 - Piracicaba, SP -
} pasilva@esalq.usp.br 
maior dificuldade de escolha pelo consumidor, principalmente pela aparência externa. Nesse sentido, é necessário ouvir as opiniões e as necessidades dos clientes, no que se refere ao abacaxi oferecido e comercializado in natura e, a partir do levantamento dessas informações, determinar as características desejadas pelo consumidor para a fruta. Segundo Mattar (1999), a forma tradicional para coleta de dados primários é por meio da comunicação direta com o detentor dos dados, sendo o dado obtido pela declaração do próprio respondente, caracterizando o uso de entrevistas e questionários. Ferreira et al. (2000) relataram que o uso de questionários como meio de coletar informações junto aos consumidores apresenta menor custo em comparação aos testes de mercado e pode ser realizado em períodos de tempo relativamente curtos.

Os consumidores indicam a estratégia de mercado para melhoria na apresentação do produto, a ser adotada pelo setor alimentício e pelos produtores agrícolas. Sabese que a satisfação ou não do consumidor pode interferir nas decisões de compra (MARCOS, 2001). Segundo Kotler (1998), a satisfação do consumidor é função das expectativas atendidas na ocasião da compra. Se o desempenho do produto adquirido não atende às expectativas, o consumidor mostra-se insatisfeito. Caso contrário, se o desempenho satisfaz as expectativas, o consumidor estará satisfeito e manterá fidelidade em relação ao produto adquirido.

A produção de frutas é suficiente para suprir o mercado, sinalizando que o novo desafio é levar até a mesa do consumidor produtos com as características por ele esperadas. $\mathrm{O}$ conhecimento e a aplicação de métodos, visando manter a qualidade dos frutos e reduzir os danos, são medidas usuais em países desenvolvidos, enquanto que, nos países em desenvolvimento, a aquisição e a aplicação do conhecimento nem sempre são bemsucedidas, uma vez que a solução para muitos problemas de manuseio dos frutos está ligada a fatores educacionais e sociológicos (ABREU et al., 1998). Segundo Vilela \& Macedo (2000), os setores envolvidos na comercialização devem observar as tendências de mercado, para identificar quais atributos dos bens têm maior valor sob a ótica do consumidor final, para aproveitar as reais oportunidades de mercado.

O presente trabalho teve como objetivo identificar o perfil dos consumidores de abacaxi, quanto às preferências, exigências, reclamações e comportamento de compra.

A pesquisa foi realizada no Mercado Municipal de Piracicaba (SP), no mês de julho de 2005, onde foram realizadas entrevistas individuais com 85 clientes, segundo o método QFD (CHENG et al., 1995). Consideraram-se como público-alvo, os consumidores, ou seja, as pessoas que se encontravam nas bancas de abacaxis, não se privilegiando quaisquer grupos de consumidores, conforme indicado por Cheng et al. (1995). Optou-se por realizar a entrevista de forma individual, utilizando questionário contendo oito perguntas para a determinação do perfil dos consumidores, destacando-se: (1) dados pessoais; (2) motivo da compra; (3) determinação das variedades conhecidas pelos consumidores; (4) grau de satisfação quanto à qualidade do abacaxi; (5) características observadas no momento da compra; (6) freqüência de compra; (7) conceito de produto ideal; (8) se o consumidor pagaria um valor mais elevado por um abacaxi de qualidade.

Foi realizada uma análise gráfica dos dados e definiuse o grau de importância dos itens citados pelos consumidores, considerando-se a classe modal, a que mais vezes foi citada, como grau requerido no item. De posse dos dados definiu-se a qualidade planejada para o abacaxi e aplicou-se o método afetivo utilizando abacaxis que continham as características indicadas pelo consumidor. Esta etapa contou com a participação de 100 consumidores, os quais foram solicitados a avaliar os abacaxis cortados em fatias de $1 \mathrm{~cm}$ de espessura e a atribuir, em escala hedônica (MEILGAARD et al., 1991), notas de 0 (desgostei extremamente) a 9 (gostei extremamente), para os atributos aparência interna, sabor, suculência e aparência externa. Para a avaliação deste último item, os frutos foram dispostos em bandeja branca sobre a bancada de provação.

Verificou-se que, 68,6\% dos entrevistados eram do sexo feminino, indicando que a mulher é a responsável pelas compras de alimentação na família, que segundo Marcos (2001) são mais exigentes e demonstram maior atenção aos detalhes com maior cuidado na escolha do produto, fato observado neste levantamento. Nos dias de pesquisa, observou-se que o motivo pelo qual o consumidor é levado a adquirir abacaxi, foi a maior intenção de consumo de abacaxi na forma in natura, correspondendo a $74,3 \%$ da preferência. Enquanto que $51,4 \%$ dos consumidores compram abacaxi para o preparo de sucos e $25,7 \%$ adquirem abacaxi para confecção de doces. A preferência do consumidor de abacaxi para consumo in natura, reforça a idéia de garantir a manutenção da qualidade do produto, haja vista que a aparência do mesmo constitui um fator decisivo da compra (KADER, 2002).

A maioria dos consumidores entrevistados $(82,9 \%)$ tinha conhecimento das cultivares comercializadas, sendo

Ciênc. agrotec., Lavras, v. 31, n. 2, p. 563-569, mar./abr., 2007 
as mais citadas pelos consumidores, a Pérola e a Smooth Cayenne, indicada por $45,7 \%$ dos entrevistados; $31,4 \%$ disseram que apenas conheciam a 'Pérola' e 5,7\% apenas a 'Smooth Cayenne'. Ao serem questionados sobre a preferência, 74,3\% dos entrevistados afirmaram que preferiam o abacaxi 'Pérola'; 5,7\% elegeram o abacaxi 'Havaí' e 20\% afirmaram que não têm preferência. Quando indagados sobre o motivo da preferência do abacaxi 'Pérola', os consumidores enumeraram as seguintes características: doçura, maciez, odor agradável, baixa acidez e sabor agradável. Entre os que preferiam o Havaí, os entrevistados destacaram a baixa acidez do mesmo.

Durante o período da pesquisa, $80,1 \%$ dos consumidores estavam insatisfeitos quanto à qualidade do abacaxi, apontando a elevada acidez como a principal causa do descontentamento, seguido do abacaxi com presença de danos físicos (incluindo amassados, manchas escuras, podridões) e frutas passadas, conforme descrito na Figura 1. O abacaxi, como a maioria das outras frutas, é classificado como perecível. Essa característica, quando aliada ao manuseio inadequado pelos membros da cadeia de comercialização, pode gerar prejuízos tanto aos agentes de comercialização quanto ao consumidor final. A exposição do produto nas gôndolas do varejo, por tempo prolongado, contribui com o aumento das perdas. Este fato é capaz de promover a diminuição da qualidade do produto, gerando insatisfação por parte dos consumidores (SHEWFELT, 2000). Somente através do estabelecimento de um novo sistema de padrões, procurando traduzir e transmitir as exigências dos consumidores em características de qualidade poder-se-á atender às expectativas dos mesmos (ANDREUCCETTI et al., 2005).

$\mathrm{Na}$ hora de comprar o abacaxi, alguns entrevistados tomavam a fruta na mão e listavam as características que gostariam que estivessem presentes e indicavam as que não gostariam de encontrar, muitas vezes indicando a fruta que comprariam e a que recusariam. Essas características foram resumidas e agrupadas na Figura 2. Observa-se que o consumidor associa a coloração da casca com o grau de maturação da fruta, pois $60,0 \%$ dos entrevistados preferem abacaxis de casca verde-amarelada a amarelada, concordando com o indicado por Chitarra \& Chitarra (1990), que os produtos de cor forte e brilhante são os mais procurados pelos consumidores, pois estes correlacionam as mudanças de coloração, por ocasião do amadurecimento, com o aumento da doçura e das características sensoriais. Dessa maneira, normalmente a decisão de compra recai sobre produtos coloridos, no caso do abacaxi, principalmente sobre aqueles que apresentam a coloração da casca tendendo ao amarelo.

A aparência foi uma das características mais indicadas pelos consumidores, $14,3 \%$ dos entrevistados, o que vem ao encontro do enunciado por Kader (2002), em que $83 \%$ da decisão de adquirir ou rejeitar um produto é determinado pela aparência ou condição em que o mesmo se encontra (Figura 2).

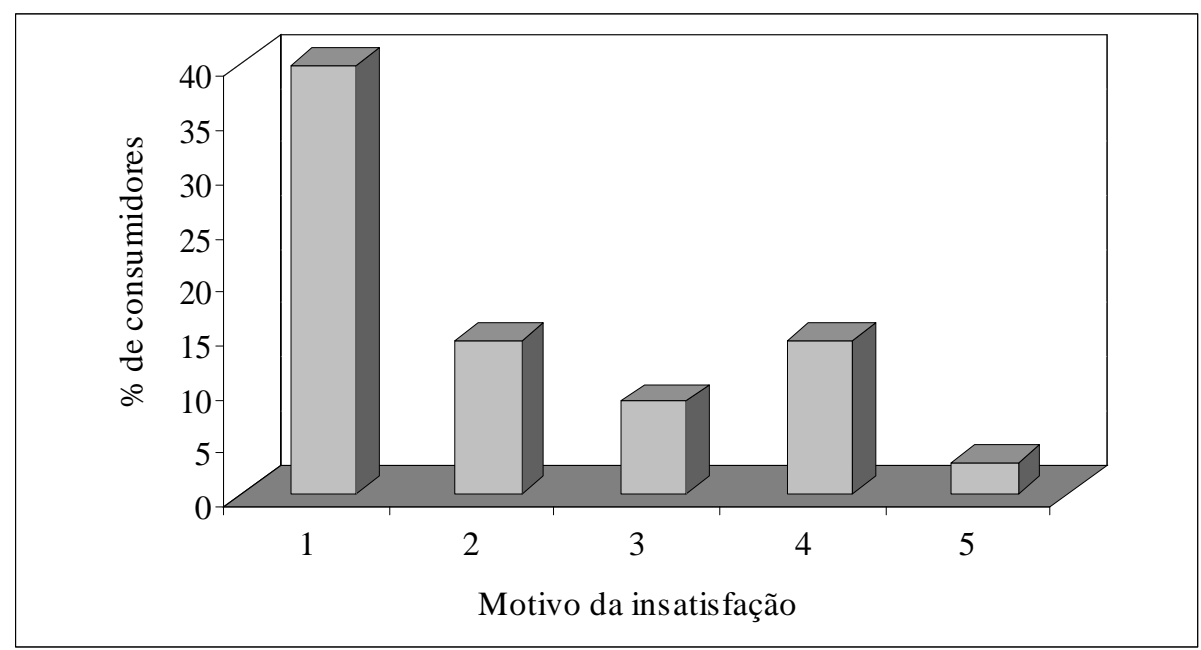

FIGURA 1 - Motivos da insatisfação do consumidor em relação ao abacaxi. 1=abacaxis ácidos, 2=polpa com manchas escuras, $3=$ presença de podridões, $4=$ frutas estragadas, 5=abacaxis passados. 


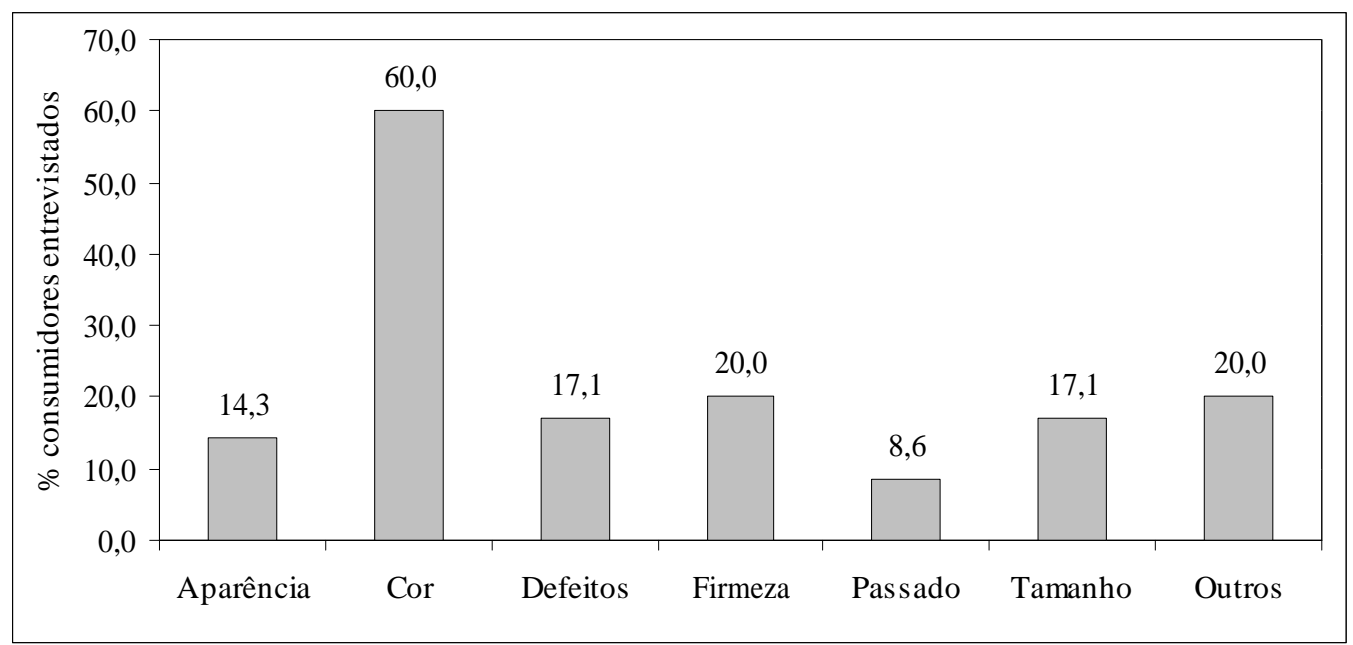

FIGURA 2 - Características observadas pelos consumidores entrevistados no Mercado Municipal de Piracicaba, no momento da compra de abacaxi.

A prática de apertar o abacaxi para verificar sua integridade é realizada por 20,0\% dos entrevistados; $8,6 \%$ observam e recusam abacaxis passados; $17,1 \%$ observam se há defeitos na casca do abacaxi, incluindo danos mecânicos (perfurações, amassados) ou qualquer anormalidade externa evidente. O tamanho é observado por $17,1 \%$ dos compradores de abacaxi; outras observações, como facilidade de retirada das folhas da coroa e preço, foram lembradas por $17,1 \%$ e por $2,9 \%$ dos consumidores, respectivamente.

Baseado na coleta de dados definiu-se o grau de importância seguindo-se o modelo de Cheng et al. (1995), com uma escala balanceada e com ponto neutro, de cada item avaliado, ou seja: (1) aparência externa (ausência de defeitos, de frutas machucadas ou com alguma lesão), (2) coloração - Amarelada - Mista (verde-amarelada), (3) tamanho da fruta (Média, grande e pequena), (4) estágio de desenvolvimento da fruta (madura), (5) textura (firmeza, suculência), (6) aparência interna (polpa de boa aparência e características adequadas), (7) aroma característico, (8) baixa acidez, (9) sabor doce.

O grau de importância atribuído pelos entrevistados à aparência externa do abacaxi 'Pérola', está representado na Figura 3, na qual se observa que a maioria das pessoas (37) considera este item importante e 16 pessoas consideram a aparência externa "muito importante".

$\mathrm{O}$ número de pessoas que apresentaram preferência pela coloração amarela é muito próximo ao número de entrevistados que elegeram a coloração verde-amarelada como preferida, não sendo possível identificar qual cor é mais aceita ou se as duas cores têm a mesma proporção de aceitação (Tabela 1).

Para avaliação do item tamanho, foram apresentadas aos entrevistados as opções, médio, grande ou pequeno, antes de escolher o grau de importância para esta característica, cuja intenção foi identificar qual tamanho é mais aceito no mercado. As distribuições para tamanhos, médio e grande, foram semelhantes e estão apresentadas na Tabela 1. A maioria das pessoas indicou que os frutos de tamanho pequeno não apresentam nenhuma importância, podendo inferir que estes são rejeitados pelo consumidor.

Para avaliação do estádio de desenvolvimento, o consumidor foi questionado quanto ao grau de importância que o abacaxi esteja maduro. A maioria dos entrevistados indicou que a presença de abacaxis maduros, no ponto para o consumo é considerada importante (I) a muito importante (MI) (Tabela 1).

Quanto à avaliação da firmeza (item Textura Firmeza), os consumidores do Mercado Municipal de Piracicaba indicaram que este atributo apresenta elevado grau de importância. Pode-se dizer que o item suculência (Textura - Suculência) só obteve respostas para os graus de importância "I" e "MI", sendo que a classe muito importante (MI) foi a mais citada. Foram encontradas as respostas, muito importante seguida da importante, indicando a relevância da qualidade visual no interior da fruta. Kader (2002) relata que o consumidor de frutas e hortaliças avalia primeiramente a coloração destas e

Ciênc. agrotec., Lavras, v. 31, n. 2, p. 563-569, mar./abr., 2007 
posteriormente a textura, e como o consumidor não tem acesso à visualização do interior da fruta, utiliza sua experiência anterior para avaliar o produto (Tabela 1).

Para o item aroma característico, a maioria dos entrevistados indicou que o aroma doce está entre as classes, importante (I) e muito importante (MI), revelando que o consumidor o relaciona com a maturação (Tabela 1). A distribuição encontrada no Mercado Municipal para o item baixa acidez indica que este item foi considerado importante para 24 entrevistados e muito importante para 33, o que mostra que o abacaxi com baixa acidez é mais aceito. A avaliação do item sabor doce indicou que, para a maioria dos entrevistados, esta característica é considerada importante a muito importante, indicando que a doçura é relevante na qualidade da fruta. Estes resultados concordam com a preferência dos entrevistados em consumir o abacaxi in natura (Tabela 1).

Quanto à freqüência de compra do abacaxi, identificou-se que $42,9 \%$ o fazem uma vez por semana, $8,6 \%$ duas vezes, $11,4 \%$ a cada quinze dias, $28,6 \%$ uma vez por mês, $2,9 \%$ a cada dois meses e $5,7 \%$ a cada três meses. A maior freqüência de compra é realizada por pessoas casadas $(74,3 \%)$, levando à percepção de que no preparo de alimentos em casa, o consumo de frutas, é habitual nas famílias. Tais informações são importantes tanto aos varejos (tipo quitanda e sacolões) quanto às redes de supermercado, pois podem constituir uma logística de venda que atenda à demanda e satisfaça os consumidores.

Os consumidores foram questionados sobre o que seria, na opinião deles, um abacaxi ideal para consumo.
Identificou-se que seria aquele que apresentasse casca sem defeitos, coloração amarelada ou mista, tamanho grande, boa aparência interna demonstrando que está sadio, textura firme, aroma característico, baixa acidez, sabor doce e que estivesse maduro do ponto de vista fisiológico e suculento.

Os consumidores alegaram $(88,6 \%)$ que se o abacaxi estivesse com o aspecto ideal por eles apontados, pagariam um preço mais elevado e 5,7\% disseram que não pagariam ou que depende da diferença de valor. De acordo com Owen et al. (2002), os consumidores apresentam uma faixa de aceitação de preços do abacaxi e são sensíveis às bruscas alterações dos mesmos.

$\mathrm{Na}$ avaliação da satisfação do consumidor, foi aplicado o teste afetivo, utilizando frutas que continham as seguintes características: ótima aparência externa, sem defeitos; coloração verde-amarelada (mista); forma característica da variedade; madura fisiologicamente; textura firme; suculento; ótima aparência interna; sabor doce (Sólidos Solúveis (SS): $12,0^{\circ}$ Brix); baixa acidez (Acidez Titulável (AT): 0,670 g ácido cítrico. $100 \mathrm{~mL}^{-1}$; SS/AT: 17,91), e que atendeu aos padrões exigidos pelo sistema de Classificação para o abacaxi (CEAGESP, 2000), ou seja, tinham sólidos solúveis mínimo de $12,0^{\circ} \mathrm{Brix}$; coloração mista (verde-amarelada); e Categoria Extra. Verificou-se que o abacaxi foi muito bem aceito, pois $79 \%$ dos consumidores atribuíram notas 8 e 9 (gostei muito e gostei extremamente) e $21 \%$ atribuíram notas 6 e 7 (gostei ligeiramente e gostei moderadamente), para o item aparência interna (Tabela 2).

TABELA 1 - Número de respostas obtidas sobre o grau de importância dos itens avaliados no Mercado Municipal de Piracicaba, para definir a qualidade do abacaxi comercializado.

\begin{tabular}{lccccc}
\hline \multirow{2}{*}{ Itens avaliados } & \multicolumn{3}{c}{ Grau de importância } \\
\cline { 2 - 6 } & NI* & PI* & AI* & $\mathbf{I}^{*}$ & MI* \\
\hline Aparência externa & 2 & 1 & 4 & 37 & 16 \\
Coloração mista (verde-amarelada) & 11 & 9 & 8 & 24 & 8 \\
Coloração amarelada & 11 & 8 & 9 & 26 & 9 \\
Tamanho pequeno & 5 & 1 & 8 & 36 & 10 \\
Tamanho médio & 14 & 5 & 5 & 13 & 24 \\
Tamanho grande & 40 & 5 & 3 & 6 & 8 \\
Estádio de desenvolvimento & 1 & 0 & 2 & 28 & 29 \\
Firmeza & 2 & 1 & 1 & 29 & 27 \\
Suculência & 0 & 1 & 2 & 18 & 39 \\
Aparência interna & 0 & 0 & 0 & 22 & 38 \\
Aroma característico & 1 & 0 & 2 & 17 & 40 \\
Baixa acidez & 0 & 0 & 3 & 24 & 33 \\
Sabor doce & 0 & 0 & 0 & 14 & 46 \\
\hline
\end{tabular}

*NI = Nenhuma Importância; PI = Pouca Importância; AI = Alguma Importância; I = Importante; MI = Muito Importante. 
TABELA 2 - Distribuição das notas para cada item avaliado no teste piloto em pesquisa realizada no Mercado Municipal de Piracicaba.

\begin{tabular}{ccccc}
\hline \multirow{2}{*}{ Notas } & \multicolumn{4}{c}{$\mathbf{N}^{\circ}$ de respostas para os itens avaliados } \\
\cline { 2 - 5 } & Aparência interna & Sabor & Suculência & Aparência externa \\
\hline 0 & - & - & - & - \\
1 & - & - & - & - \\
2 & - & - & - & - \\
3 & - & - & - & - \\
4 & - & - & - & - \\
5 & - & - & 2 & - \\
6 & 7 & 5 & 13 & 5 \\
7 & 14 & 12 & 57 & 61 \\
8 & 55 & 60 & 28 & 24 \\
9 & 24 & 23 & & \\
\hline
\end{tabular}

Em relação ao sabor, observa-se na Tabela 2, que $83 \%$ dos participantes do teste atribuíram notas 8 e 9 (gostei muito e gostei extremamente); $17 \%$ atribuíram notas de 6 a 8 (gostei ligeiramente a gostei muito), indicando boa aceitação do abacaxi pelos consumidores.

Constatou-se que $57 \%$ dos entrevistados atribuíram a nota 8 (gostei muito) para o item suculência e que a nota mais baixa foi a 6 (gostei ligeiramente), a qual perfez apenas, $2 \%$ dos consumidores. Estes resultados indicam que o abacaxi apresentado estava de acordo com as expectativas indicadas pelo consumidor quando se efetuou o levantamento dos atributos relevantes (Tabela 2).

A avaliação da aparência externa mostra que o lote piloto foi muito bem aceito neste quesito pelos freqüentadores do Mercado Municipal, a maior parte dos entrevistados (95\%) atribuiu notas satisfatórias, ou seja, acima de 6 (gostei ligeiramente) (Tabela 2).

Conclui-se, portanto, que o método QFD foi eficiente na avaliação do abacaxi variedade Pérola. A pesquisa e o teste hedônico revelaram que os consumidores buscam frutas sem defeitos, de tamanho médio a grande, maduras, firmes, suculentas, de boa aparência interna, que sejam de coloração amarelada ou verde-amarelada, e que apresentem aroma característico, baixa acidez e sabor doce.

Diante da insatisfação dos consumidores e considerando-se que o abacaxi é consumido preferencialmente in natura, deve-se atentar para a preservação da sua aparência e qualidade sensorial. A opinião dos consumidores deve ser considerada na tentativa de identificar os pontos que devem ser melhorados dentro da cadeia de comercialização, a fim de minimizar as perdas e promover a melhoria e a manutenção da qualidade do produto final.

\section{AGRADECIMENTOS}

À FAPESP, pelo apoio financeiro para a realização deste trabalho e aos profissionais do Centro de Qualidade em Horticultura da CEAGESP.

\section{REFERÊNCIAS BIBLIOGRÁFICAS}

ABREU, C. M. P. de; CARVALHO, V. D. de; GONÇALVES, N. B. Cuidados pós-colheita e qualidade do abacaxi para exportação. Informe Agropecuário, Belo Horizonte, v. 19, n. 195 , p. 70-72, 1998.

ANDREUCCETTI, C.; FERREIRA, M. D.; TAVARES, M. Perfil dos consumidores de tomate de mesa em supermercados da região de Campinas. Horticultura Brasileira, Brasília, v. 23, n. 1, p. 148-153, jan./mar. 2005.

CHENG, L. C.; SCAPIN, C. A.; OLIVEIRA, C. A. de; KRAFETUSKI, E.; DRUMOND, F. B.; BOAN, F. S.; PRATES, L. R.; VILELA, R. M. QFD: planejamento da qualidade. Belo Horizonte: Fundação Christiano Ottoni, 1995. $261 \mathrm{p}$.

CHITARRA, M. I. F.; CHITARRA, A. B. Pós-colheita de frutos e hortaliças: fisiologia e manuseio. Lavras: ESAL/ FAEPE, 1990. $320 \mathrm{p}$.

COMPANHIA DE ENTREPOSTOS E ARMAZÉNS GERAIS DO ESTADO DE SÃO PAULO. Classificação do abacaxi (Ananas comosus $\mathrm{L}$. Merril): programa brasileiro para melhoria dos padrões comerciais e de embalagens de hortigranjeiros. São Paulo, 2000. 
FERREIRA, V. L. P.; ALMEIDA, T. C. A.; PERTTINELLI, M. L. C.; SILVA, M. A. A. P.; CHAVES, J. B. P.; BARBOSA, E. M. M. Análise sensorial: testes discriminativos e afetivos. Campinas: SBCTA, 2000. 127 p. (Manual: Série Qualidade).

KADER, A. A. Postharvest technology of horticultural crops. 3. ed. Davis: University of California, 2002. 535 p.

KOTLER, P. Administração de marketing: análise, planejamento, implementação e controle. 5. ed. São Paulo: Atlas, 1998. 725 p.

MARCOS, S. K. Desenvolvimento de tomate de mesa, com o uso do método QFD (Quality Function Deployment), comercializado em um supermercado. 2001. $199 \mathrm{f}$. Tese (Doutorado em Ciência de Alimentos) - Universidade Estadual de Campinas, Campinas, 2001.

MATTAR, F. N. Pesquisa de marketing: metodologia, planejamento. 5. ed. São Paulo: Atlas, 1999. v. 1, 339 p.
MEILGAARD, M.; CIVILLE, G. V.; CARR, B. T. Sensory evaluation techniques. 2. ed. Florida: CRC, 1991. 354 p.

OWEN, K. M.; GRIFFITH, G. R.; WRIGHT, V. E. One little Lebanese cucumber is not going to break the bank: price in the choice of fresh fruits and vegetables. Australian Journal of Agricultural and Resource Economics, Sidney, v. 46, n. 2, p. 209-231, 2002.

SOUZA, R. A. M. Mercado para produtos minimamente processados. Informações Econômicas, São Paulo, v. 31, n. 3, p. 7-18, 2001.

SHEWFELT, R. L. Consumer friendly specifications for a global marketplace. Food Australia, Sidney, v. 52, n. 7, p. 311-314, 2000.

VILELA, N. J.; MACEDO, M. C. Fluxo de poder no agronegócio: o caso das hortaliças. Horticultura Brasileira, Brasília, v. 18, n. 2, p. 88-94, 2000. 